\section{POS0955 EXTRACELLULAR MATRIX PROTEIN TURNOVER MARKERS ARE ASSOCIATED WITH AXSPA - A COMPARISON WITH CONTROL SUBJECTS WITH OR WITHOUT PELVIC, BUTTOCK OR BACK PAIN}

H. Port ${ }^{1,2}$, S. Holm Nielsen ${ }^{1,3}$, J. Blair ${ }^{1}$, S. F. Madsen ${ }^{1}$, A. C. Bay-Jensen ${ }^{1}$, M. Karsdal ${ }^{1}$, S. Seven ${ }^{4,5}$, I. J. Sørensen ${ }^{4,5}$, L. Morsel-Carlsen ${ }^{6}$, M. Østergaard ${ }^{4,5}$, S. Juhl Pedersen ${ }^{4} .{ }^{1}$ Nordic Bioscience A/S, Immunoscience, Herlev, Copenhagen, Denmark; ${ }^{2}$ Panum - University of Copenhagen, School of Health and Medical Sciences, København, Denmark; ${ }^{3}$ Technical University of Denmark, Biomedicine and Biotechnology, Kgs. Lyngby, Denmark; ${ }^{4}$ Rigshospitalet, Center for Arthritis Research, Glostrup, Denmark; ${ }^{5}$ University of Copenhagen, Clinical Medicine, København, Denmark; ${ }^{6}$ Frederiksberg Hospital, Radiology, Frederiksberg, Denmark

Background: Axial spondyloarthritis (axSpA) is a common chronic inflammatory disease, associated with extracellular matrix (ECM) remodeling of the cartilage, bone and connective tissues. The primary symptom of axSpA is back pain, caused by inflammation. However, there is a medical need to truly identify patients with axSpA from other subjects with buttock or low back pain attributable to other reasons. Tissue-derived extracellular (ECM) markers quantified in serum may serve to differentiate axSpA patients from other diagnostic entities.

Objectives: To investigate circulating ECM turnover markers as potential biomarkers to differentiate patients with axSpA from a control group of subjects with buttock or pelvic pain attributed to other reasons, including postpartum women and healthy subjects.

Methods: Biomarkers of ECM degradation/chronic inflammation (C1M, C3M, C4M, C6M, CRPM, C10C and COL10NC) and ECM formation (PRO$\mathrm{C} 3$ and PRO-C6) were measured in 204 participants from the MASH study [1] (Table 1). Biomarker levels were compared among patients with axSpA and control group, and two new variables (Type 3 and Type 6) were included, corresponding to the index of formation/degradation of type III and type $\mathrm{VI}$ collagen respectively. The biomarker data was log10 transformed for normalization when necessary and linear regression models with pairwise comparisons were performed. Clinical scores and the SPARCC MRI scores for sacroiliac joint (SIJ) inflammation were correlated with the biomarkers data (data not shown).

Table 1. Comparison of blood-tested biomarkers levels in MASH study. Data was adjusted for confounders age, gender, and body mass index (BMI).

\begin{tabular}{lccc}
\hline Biomarkers (Mean (SD)) & $\begin{array}{c}\text { Patients with axSpA } \\
(\mathrm{n}=41)\end{array}$ & $\begin{array}{c}\text { Control groups } \\
(\mathrm{n}=163)\end{array}$ & $\mathrm{p}$ \\
\hline C1M & $84.3(85.8)$ & $36.2(22.1)$ & $<0.0001$ \\
C3M & $15.6(4.0)$ & $13.9(3.0)$ & 0.011 \\
C4M & $34.9(10.2)$ & $27.9(7.7)$ & $<0.0001$ \\
C6M & $20.5(5.8)$ & $17.4(4.2)$ & $<0.0001$ \\
CRPM & $11.9(2.9)$ & $11.0(5.9)$ & 0.027 \\
C10C & $2567(462)$ & $2568(560)$ & 0.31 \\
COL10NC & $9.15(5.81)$ & $9.43(8.27)$ & 0.43 \\
PRO_C3 & $10.2(2.5)$ & $11.3(3.0)$ & 0.0052 \\
PRO_C6 & $6.94(2.45)$ & $6.86(2.53)$ & 0.93 \\
Type 3 (PRO-C3/C3M) & $0.70(0.28)$ & $0.86(0.31)$ & 0.0004 \\
Type 6 (PRO-C6/C6M) & $0.36(0.16)$ & $0.41(0.14)$ & 0.0024 \\
\hline
\end{tabular}

Results: We found that patients with axSpA had significantly increased MMP-mediated degradation of type I (C1M), type III (C3M), type IV (C4M) and type VI (C6M) collagens $(p<0.0001, p=0.01, p<0.001, p<0.001$, respectively), and CRP-metabolite (CRPM, $p=0.027$ ), and significantly decreased formation of type III collagen $(p=0.052)$ compared with control groups when adjusting for age, gender and body mass index (BMI). Significantly decreased rates of Type 3 and Type 6 variables were also observed in patients with axSpA $(p=0.004, p=0.002$, respectively). We further adjusted the analyses by the SPARCC SIJ inflammation scores since differences in these were found among the two groups [1], and similar differences in biomarker levels were found, indicating that the relationship between the level of biomarkers and the SPARCC SIJ inflammation scores was independent between the two groups.

Conclusion: Biomarkers of type I, III, IV and V collagen and a CRP-metabolite showed an altered turnover in patients with axSpA compared with the control group including subjects with or without buttock or pelvic pain attributable to other reasons. Such biomarkers may be used in combination with MRI or independently to separate patients with axSpA from other back pain conditions. REFERENCES:

[1] Seven, S., Østergaard, M., Morsel-Carlsen, L., Sørensen, I. J., Bonde, B. Thamsborg, G., ... \& Pedersen, S. J. (2019). Magnetic Resonance Imaging of Lesions in the Sacroiliac Joints for Differentiation of Patients With Axial Spondyloarthritis From Control Subjects With or Without Pelvic or Buttock Pain: A Prospective, Cross-Sectional Study of 204 Participants. Arthritis \& Rheumatology, 71(12), 2034-2046.

Acknowledgements: The study was supported by Innovation Fund Denmark, Rigshospitalet and the Danish Rheumatism Association (grant no. R102A2132-B98, R159-A5061 and R150-A4467-B98).

Disclosure of Interests: Helena Port Employee of: Industrial PhD student at Nordic Bioscience and University of Copenhagen, Signe Holm Nielsen Employee of: Full time employee at Nordic Bioscience, Joseph Blair Employee of: Full time employee at Nordic Bioscience, Sofie Falkenløve Madsen Employee of: Full time employee at Nordic Bioscience A/S, Anne-Christine Bay-Jensen Shareholder of: Nordic Bioscience A/S, Employee of: Full time employee at Nordic Bioscience A/S, Morten Karsdal Shareholder of: Nordic Bioscience A/S, Employee of: Full time employee at Nordic Bioscience A/S, Sengül Seven: None declared, Inge Juul Sørensen: None declared, Lone Morsel-Carlsen: None declared, Mikkel Østergaard: None declared, Susanne Juhl Pedersen: None declared

DOI: 10.1136/annrheumdis-2021-eular.786

\section{POS0956 \\ MEDITERRANEAN DIET IN AXIAL SPONDYLOARTHRITIS: A NUTRITIONAL INTERVENTION STUDY}

F. Ometto $^{1}$, D. M. Farber ${ }^{1}$, M. Lorenzin ${ }^{1}$, A. Ortolan ${ }^{1}$, G. Dellamaria ${ }^{2}$ M. Felicetti ${ }^{1}$, M. Favero ${ }^{1}$, R. Valentini ${ }^{2}$, A. Doria ${ }^{1}$, R. Ramonda ${ }^{1} .{ }^{1}$ University of Padova, Rheumatology Unit, Department of Medicine, DIMED, Padova, Italy; ${ }^{2}$ University of Padova, Dietetics and Clinical Nutrition Unit, Department of Medicine DIMED, Padova, Italy

Background: Mediterranean diet (MD) proved to be beneficial on disease activity in patients affected by rheumatoid arthritis. A few data are available in other rheumatic conditions.

Objectives: A prospective monocentric study was conducted to evaluate the effect of a nutritional intervention based on the MD and to investigate the impact of such modification on disease activity of axial spondyloarthitis (ax-SpA).

Methods: Patients affected by ax-SpA randomized to a nutritional intervention arm (N) or a control arm (C) and were assessed at baseline (TO) and at month 6 (T6). Patients in $\mathrm{N}$ underwent a nutritional evaluation and received suggestions for dietary modification at TO, and then every 2 months. Adherence to the MD was evaluated with the PREDIMED questionnaire (range 0-10) [1]. A multivariable regression analysis was conducted to identify independent predictors of PREDIMED and of ASDAS-CRP improvement at T6.

Results: Eligible patients (161) were randomized to either N (81) or C (80); 47 in $\mathrm{N}$ and 63 in $\mathrm{C}$ completed the study. No relevant change of anthropometric or laboratory measures was observed at T6 in either group. A $\geq 20 \%$ PREDIMED improvement was more frequent in $\mathrm{N}(22 / 47,46.8 \%)$ compared to $C(13 / 63,20.6 \%)(p<0.01)$. Also, a $\geq 20 \%$ ASDAS-CRP improvement was more frequent in $\mathrm{N}(8 / 47,57.1 \%)$ compared to $\mathrm{C}(39 / 63,40.6 \%)$ $(p=0.020)$; and especially in those who achieved a $\geq 20 \%$ PREDIMED improvement $(12 / 35,34.3 \%)$ vs those who did not $(2 / 73,2.7 \%)(p<0.01)$ The nutritional intervention, a higher age, and a lower BMI increased the odds of achieving a $\geq 20 \%$ PREDIMED improvement; the $\geq 20 \%$ PREDIMED improvement was associated higher odds of achieving a $\geq 20 \%$ ASDASCRP improvement; psoriasis was negatively associated to the ASDAS-CRP improvement (Figure 1).

Conclusion: A nutritional intervention is effective in improving adherence to the MD in ax-SpA. A higher adherence to the MD may have a beneficial impact on activity of ax-SpA. Patients with psoriasis may have a limited benefit from the dietary improvement.

\section{REFERENCES:}

[1] Martínez-González, M.A. et al. A 14-item mediterranean diet assessment tool and obesity indexes among high-risk subjects: The PREDIMED trial.PLoS One 2012,7. 